\title{
Performance Approximation and Design of Pick-and-Pass Order Picking Systems
}

\author{
Mengfei Yu and René de Koster
}

\begin{tabular}{|l|l|}
\hline \multicolumn{2}{|l|}{ ERIM REPORT SERIES RESEARCH IN MANAGEMENT } \\
\hline ERIM Report Series reference number & ERS-2007-082-LIS \\
\hline Publication & December 2007 \\
\hline Number of pages & 32 \\
\hline Persistent paper URL & http://hdl.handle.net/1765/10733 \\
\hline Email address corresponding author & myu@rsm.nl \\
\hline Address & Erasmus Research Institute of Management (ERIM) \\
& RSM Erasmus University / Erasmus School of Economics \\
& Erasmus Universiteit Rotterdam \\
& P.O.Box 1738 \\
& 3000 DR Rotterdam, The Netherlands \\
& Phone: $\quad+31104081182$ \\
& Fax: $\quad+31104089640$ \\
& Email: info@erim.eur.nl \\
& Internet: $\quad$ www.erim.eur.nl \\
\hline
\end{tabular}

Bibliographic data and classifications of all the ERIM reports are also available on the ERIM website: www.erim.eur.nl 


\section{ERASMUS RESEARCH INSTITUTE OF MANAGEMENT}

\section{REPORT SERIES}

\section{RESEARCH IN MANAGEMENT}

\begin{tabular}{|l|l|}
\hline ABSTRACT AND KEYWORDS \\
\hline Abstract & $\begin{array}{l}\text { In this paper, we discuss an approximation method based on G/G/m queuing network modeling } \\
\text { using Whitt's (1983) queuing network analyzer to analyze pick-and-pass order picking systems. } \\
\text { The objective of this approximation method is to provide an instrument for obtaining rapid } \\
\text { performance estimates (such as order lead time and station utilization) of the order picking } \\
\text { system. The pick-and-pass system is decomposed into conveyor pieces and pick stations. } \\
\text { Conveyor pieces have a constant processing time, whereas the service times at a pick station } \\
\text { depend on the number of order lines in the order to be picked at the station, the storage policy at } \\
\text { the station, and the working methods. Our approximation method appears to be sufficiently } \\
\text { accurate for practical purposes. It can be used to rapidly evaluate the effects of the storage } \\
\text { methods in pick stations, the number of order pickers at stations, the size of pick stations, the } \\
\text { arrival process of customer orders, and the impact of batching and spliting orders on system } \\
\text { performance. }\end{array}$ \\
\hline Free Keywords & pick-and-pass, order picking, warehousing, queuing network, simulation \\
\hline Availability & $\begin{array}{l}\text { The ERIM Report Series is distributed through the following platforms: } \\
\text { Academic Repository at Erasmus University (DEAR), DEAR ERIM Series Portal }\end{array}$ \\
Social Science Research Network (SSRN), SSRN ERIM Series Webpage \\
Research Papers in Economics (REPEC), REPEC ERIM Series Webpage
\end{tabular}




\title{
Performance Approximation and Design of Pick-and-Pass Order Picking Systems
}

\author{
Mengfei Yu , René de Koster \\ RSM Erasmus University Rotterdam, The Netherlands
}

\begin{abstract}
In this paper, we discuss an approximation method based on $G / G / m$ queuing network modeling using Whitt's (1983) queuing network analyzer to analyze pick-and-pass order picking systems. The objective of this approximation method is to provide an instrument for obtaining rapid performance estimates (such as order lead time and station utilization) of the order picking system. The pick-and-pass system is decomposed into conveyor pieces and pick stations. Conveyor pieces have a constant processing time, whereas the service times at a pick station depend on the number of order lines in the order to be picked at the station, the storage policy at the station, and the working methods. Our approximation method appears to be sufficiently accurate for practical purposes. It can be used to rapidly evaluate the effects of the storage methods in pick stations, the number of order pickers at stations, the size of pick stations, the arrival process of customer orders, and the impact of batching and splitting orders on system performance.
\end{abstract}

Key words: Pick-and-pass, order picking, warehousing, queuing network, simulation.

\section{Introduction}

Order picking, the process of picking products to fill customer orders, is one of the most important activities in warehouses due to its high contribution (about 55\%) to the total warehouse operating cost (Tompkins et al., 2003). This paper considers a common type of pickand-pass order picking system, which consists of a conveyor connecting all pick stations located along the conveyor line, as sketched in Figure 1. Storage shelves are used to store products at each pick station. A customer order contains several order lines (an order line is a number of units of one article). A bin is assigned to a customer order together with a pick list when it arrives at the order picking system. To fill an order, the order bin is transported on the conveyor passing various pick stations. If an order line has to be picked at a station, the transportation 
system automatically diverts the bin to the station, so that the main flow of bins cannot become blocked by bins waiting for picking. After entering the pick station, the order bin moves to the pick position. Order pickers are assigned to pick stations to fill customer orders. An order bin is processed by one order picker at a station and an order picker works on one order at a time. This paper assumes the order picker picks one order line per picking trip. The picker starts his trip from the pick position, reads the next article on the bin's pick list, walks to the storage shelves indicated, picks the required article, goes back to the pick position and deposits the picked article into the bin. Although in some systems multiple lines may be picked in a picking tour, we model the case where only one article is picked per trip. Systems that we have observed that adhere to this constraint include a parts Distribution Center (DC) of an international motor production company (we use this example in our model validation in section 4) where one article is picked per trip since articles are relatively heavy and need to be barcode scanned. In another warehouse we studied, even light articles were not batched to reduce pick errors. Having finished the pick list, the order picker pushes the bin back onto the main conveyor, which transports the bin to a next pick station. Such pick-and-pass systems are typically applicable in case of a large daily number of multi-line orders. De Koster (1996) summarizes the advantages of such order picking systems.

Recent trends in warehouses show that companies tend to accept late orders while providing rapid and timely delivery within tight time window, which implies time available for order picking becomes shorter (De Koster et al. 2007). Hence, minimizing order throughput time is an important objective in many warehouses, and it is used commonly in order picking literature (see Le-Duc and De Koster 2007, Chew and Tang 1999, and Roodbergen 2001). Exact analysis of a pick-and-pass system described above is difficult due to the large state space in modeling bin positions on the conveyor and difficulties in obtaining the exact distribution of service time at stations. This paper proposes an approximation-based modeling and analysis method to evaluate the mean order throughput time in such systems. The method provides a fast tool to evaluate alternatives in designing pick-and-pass systems. Our model relaxes the Jackson queuing network modeling of De Koster (1994) by allowing a general order arrival process and general service time distributions, which represent real-life warehouses more accurately and provide a deeper understanding of the pick-and-pass order picking system. The modeling and the analysis of the system is based on the analysis of a $G / G / m$ queuing network by Whitt (1983). We show the 
approximation method leads to acceptable results by comparing it with both simulation and with the real order picking process at a parts DC of an international motor production company.

The paper is organized as follows: In section 2, we review literature on order picking, storage, zoning, and order batching issues. Section 3 describes the approximation model followed by model validation in section 4. In section 5, we analyze the impact of different warehousing activities on the system performance. We draw conclusions and discuss possible extensions of this paper in section 6 .

\section{Literature review}

Literature on order picking processes distinguishes between parts-to-picker and picker-to-parts picking systems according to whether parts are automatically retrieved by machines and brought to pick stations for manual picking, or pickers travel along the picking locations to retrieve the items. A comprehensive literature overview on parts-to-picker order picking systems is given by Van den Berg (1999), Roodbergen (2001), Le Duc (2005), and Gu et al. (2007). Picker-to-parts order picking systems are widely used in warehouses. Researchers pay attention to the following four issues influencing the order picking system performance: storage, batching, routing and zoning. A recent literature review is given by De Koster et al. (2007).

Storage assignment is the way to assign products to their locations. Mainly three storage policies are mentioned in literature: random storage, full turn-over based storage, and picking-frequency class-based storage. In random storage, products are randomly assigned to available storage locations. Random storage is the simplest way to assign products to their locations and is often used as a benchmark to compare with other storage policies. In a full-turnover based storage policy, storage space is reserved for each product according to its turnover rate. A large part of the literature on full turnover-based storage policies focuses on Cube-per-Order Index (COI) based storage. The COI of an item is defined as the ratio of the item's total required space to the number of trips required to satisfy its demand per period. Articles with low COI are placed closest to the picking depot (the start and finish position of a picking route). Jarvis (1991) proves that the COI based storage policy is optimal in minimizing the expected travel distance per order. Caron et al. (1998) develop an efficient COI-based product-to-location assignment policy with the objective to minimize the expected travel distance in a picking tour. In practice, pickfrequency class-based storage is the most popular storage policy used in warehouses. Products 
are classified according to their pick frequencies and are stored in classes. Within each class, items are randomly stored. Petersen et al. (2004) analyze the relation between the number of product classes and the pickers' travel time in picker-to-parts order picking systems by simulation.

Order batching is the process of grouping customer orders together and jointly releasing them for picking. Order batching reduces the average travel time per order since picking tours are shared between orders. Gademann et al. (2001) and Gademann and Van De Velde (2005) consider the order batching problem with objectives to minimize the maximum lead time of a batch and the total order picking travel time. Both problems are NP-hard and they design algorithms to solve problems of modest size to optimality. Elsayed and Stern (1983), Hwang et al. (1988), Gibson and Sharp (1991), Pan and Liu (1995), and Elsayed and Unal (1989) propose so called seed and saving heuristic algorithms to batch orders to minimize order picking time. De Koster et al. (1999) perform a comparative study for these algorithms and conclude that even simple order batching methods lead to significant picking time savings compared to the firstcome first-serve batching rule. Chew and Tang (1999) and Le-Duc and De Koster (2006) set up stochastic models and use queuing theory to analyze the order batching methods. They provide bounds and an approximation solution for the average order throughput time.

Routing is the problem to decide the travel route for pickers to retrieve products. It is a special case of the well-known Traveling Salesman Problem. Ratliff and Rosenthal (1983) use dynamic programming to find an optimal route for a rectangular, narrow aisles and single-block warehouse. De Koster et al. (1998) and Roodbergen and De Koster (2001) extend the method for a warehouse where the I/O point location is decentralized and warehouses with a middle aisle (2 blocks). Instead of the optimal routing methods, heuristics are commonly used in practice because they are easy to implement and maintain. The two popular heuristic routing methods are the S-shape (any aisle containing at least one pick is traversed entirely, except potentially the last visited aisle) and the return heuristics, in which an order picker enters and leaves an aisle from the same end.

Zoning is the problem of dividing the whole picking area into a number of small areas (zones), each with one or a few order pickers. The major advantages of zoning are: reduction of the travel time (because of the smaller traversed area and also the familiarity of the pickers with the zone) and of the traffic congestion. The analysis on zoning is classified into synchronized zoning, 
where all zone pickers work on the same batch of orders at the same time, and progressive zoning, where each batch of orders (or one order) is processed at one zone at a time. In progressive zoning, the batch of orders is passed from one zone to the next, which is why such systems are also called pick-and-pass systems. Jane and Laih (2005) consider heuristics to assign products to zones with the objective to balance the work load between zones in a synchronized order picking system. Le-Duc and De Koster (2005) consider the problem of determining the optimal number of zones (for a given picking area) in a pick-and-pack order picking system to minimize the mean order throughput time. For progressive zoning, Jane (2000) proposes several heuristic algorithms to balance the work load among order pickers in zones. De Koster (1994) approximates pick-and-pass order picking systems by means of Jackson network modeling and analysis. His model assumes the service time at each pick station is exponentially distributed and customer orders arrive according to a Poisson process. Jewkes et al. (2004) is the only other paper considering pick-and-pass order picking system we found. They determine the optimal pick position of an order bin in a pick station, the optimal product location in pick stations, and the size of pick stations with the objective of minimizing the order throughput time. Since they consider a static setting, only travel time to pick orders is considered in their paper. This paper considers a dynamic setting, where the waiting times of an order bin in front of pick stations is taken into account.

\section{Approximation model}

The pick-and-pass order picking system is represented by a sequence of pick stations connected by conveyor pieces (see Error! Reference source not found.).

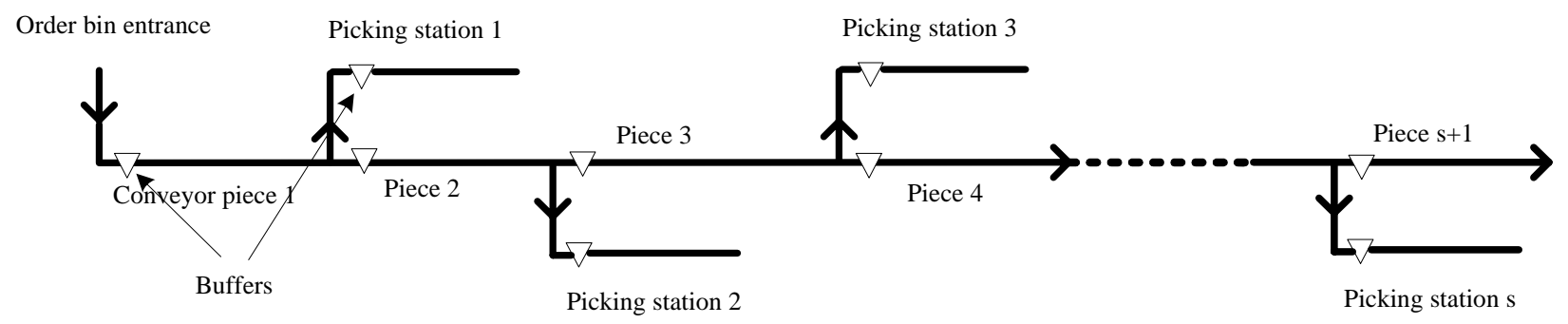

Figure 1: Illustration of the pick-and-pass order picking system.

The service time for an order bin at a pick station consists of several components: setup time (time for starting and finishing the pick list, checking, weighing, labeling, etc.), travel time, and the picking time for order lines. Travel time depends on the number of order lines to be picked at 
the station, the location of these order lines in the pick station, and the travel speed of pickers. Picking time is proportional to the number of order lines to be picked in the station. We assume setup time and pickers' travel speed are constants. We also assume the picking time per order line, which may consist of multiple units, is constant, and independent of the product type and the number of units picked. These assumptions will be reasonable when the variance of the units picked per order line and the pick time itself are small. We suppose a pick-frequency class-based storage policy (see section 2) in each station. Similar to other research (see e.g. Petersen et al. 2004), we assume demand is uniformly distributed over the products within a product class. The service time at a pick station is modeled as having a general distribution and is characterized only by its mean and Squared Coefficient of Variation (SCV). It is reasonable to use only two moments because in reality service time is hard to fit a theoretical distribution, whereas the information on mean and the variance of service time is relatively easy to obtain.

A conveyor piece $j$ can contain $k_{j}$ order bins and is assumed to have constant speed, $v l_{j}$. We approximate it as $k_{j}$ servers in parallel, each of which has constant service rate of $v l_{j} / k_{j}$. This means that the output rate of a conveyor piece $j$ equals exactly $v l_{j}$ if and only if it is completely full with bins. In the approximation, the output rate of a conveyor piece is proportional to the number of bins on it. At the end of a conveyor piece, a transition is made by the order bin to the subsequent conveyor piece, or it is pushed into a pick station. The transition probability of an order bin to enter a pick station depends on the bin's pick list and the storage assignment of products in that station. We approximate this behavior by Markovian transition probability, which is justified in case of a large number of bins (the typical application area of these systems). The transition probabilities at the end of a conveyor piece and at leaving a pick station are calculated in section 3.2. After finishing the picking at a station, the bin is pushed onto a conveyor piece downstream the pick station.

We assume each pick station has infinite storage capacity (buffer) for order bins. This assumption is reasonable because in reality order pickers at pick stations will ensure that the system will not be blocked when their stations become full. If a pick station tends to become full, the order pickers can temporarily put the bins on the floor. We also assume there is a buffer with infinite capacity in front of each conveyor piece, which means that the arrivals will not be lost and pick stations and conveyor pieces can not become blocked because of lack of output capacity. 
This assumption is also realistic because the conveyor pieces can normally contain a sufficiently large number of bins.

The whole pick-and-pass order picking system is modeled approximately as a $G / G / m$ queuing network consisting of $C+S$ nodes preceded by unlimited waiting space in front of them. Nodes $1,2, \ldots C$ represent conveyor pieces and nodes $C+1, C+2, \ldots C+S$ represent pick stations. The number of servers at each node equals the capacity of each conveyor piece or the number of order pickers working in the station.

The data used to analyze the queuing network are as follows:

$S: \quad$ the number of pick stations, with index $j$.

$C: \quad$ the number of conveyor pieces, with index $j$.

$J$ : the total number of nodes, equals to $S+C$, with index $j$.

$I$ : $\quad$ the number of product classes stored in the pick stations, with index $i$.

$N$ : the maximum number of order lines contained in a customer order, with index $n$.

$O_{n}: \quad$ probability that an order contains $n$ order lines, $n=1,2, \ldots N$.

$f_{i}$ : order frequency of product class $i$, it is the probability that an order line belongs to the $i$ th product class, $i=1,2, \ldots I$.

$v l_{j}: \quad$ the velocity of conveyor piece $j$, expressed in bins per second $j=1,2, \ldots C$.

$k_{j}$ : the capacity of conveyor piece $j$, expressed in bins. $j=1,2, \ldots C$.

$h_{j}$ : the number of order pickers at station $j, j=C+1, C+2, \ldots C+S$.

$m_{j}$ : the number of servers at node $j, m_{j}=k_{j}$ for $j=1,2, \ldots C$, and $m_{j}=h_{j}$ for $j=C+1, C+2, \ldots C+S$.

$l_{i j}: \quad$ the storage space (in meter) used to store products of the $i$ th class on the racks at station $j, i=1,2, \ldots I, j=C+1, C+2, \ldots C+S$.

SC: $\quad$ setup time per bin at a pick station, expressed in seconds.

tp : $\quad$ picking time for one order line, expressed in seconds.

$\lambda_{01}$ : external arrival rate of order bins to the system, entering node 1, expressed in bins/second.

$c_{01}^{2}: \quad$ SCV of inter-arrival time of order bins to the system.

The variables are as follows: 
$V_{j}$ : probability of visiting station $j$ for an order bin, $j=C+1, C+2, \ldots C+S$.

$\tau_{j}$ : total service time at station $j$ if the order bin enters station $j, j=C+1, C+2, \ldots C+S$.

$w k_{j}$ : total travel time at station $j$ if the order bin enters station $j, j=C+1, C+2, \ldots C+S$.

$p k_{j}$ : total picking time at station $j$ if the order bin enters station $j, j=C+1, C+2, \ldots C+S$.

$c_{s j}^{2}: \quad$ SCV of service time at node $j, j=1,2, \ldots C+S$.

$c_{a j}^{2}: \quad$ SCV of inter-arrival time to node $j, j=1,2, \ldots C+S$.

$\lambda_{j}: \quad$ internal arrival rate of order bins to node $j, j=1,2, \ldots C+S$.

$q_{k j}: \quad$ transition probability from node $k$ to node $j, k=1,2, \ldots C+S, j=1,2, \ldots C+S$.

$v t_{j}: \quad$ number of visits of an order bin to node $j$ (either 0 or 1 ), $j=1,2, \ldots C+S$.

$W_{j}$ : waiting time of an order bin in front of node $j, j=1,2, \ldots C+S$.

$T_{j}: \quad$ sojourn time of an order bin at node $j, j=1,2, \ldots C+S$.

In the next two subsections, we will derive expressions for the mean and the SCV of the service time at each node and then calculate the mean throughput time of an order bin in the system.

\subsection{Mean and SCV of service times at pick stations and conveyor pieces}

The mean service time at station $j$ if the order bin enters station $j$, has three components, setup time $s c$, travel time $w k_{j}$, and the picking time $p k_{j}$. The mean service time is calculated by

$$
E\left[\tau_{j}\right]=s C+E\left[w k_{j}\right]+E\left[p k_{j}\right] \quad \forall j>C
$$

We next derive the expressions for the last two components in equation (1).

The probability that an order line of class $i$ is stored in station $j$ depends on the order frequency of the $i$ th class products and the space used to stored the $i$ th class products in station $j$. It is given by

$$
p_{i j}=f_{i} * \frac{l_{i j}}{\sum_{j=1}^{S} l_{i j}} \quad \forall i, \forall j>C
$$

Therefore, the probability that an order line is picked in station $j$ is the summation of $p_{i j}$ over $i$. 


$$
P_{j}=\sum_{i=1}^{I} p_{i j} \quad \forall j>C
$$

So the conditional probability of an order bin to enter station $j$ given that there are $n$ order lines in the order equals the probability that there is at least one order line to be picked at station $j$ :

$V_{j n}=1-\left(1-P_{j}\right)^{n} \quad \forall j>C, \quad \forall n$

Where $\left(1-P_{j}\right)^{n}$ is the probability that none of the order lines in this order bin is to be picked in station $j$. The probability of an order bin to enter station $j$ now becomes:

$V_{j}=\sum_{n=1}^{N} V_{j n} * O_{n} \quad \forall j>C$

The number of order lines to be picked in station $j$ given that the order bin contains $n$ order lines is a random variable with binomial distribution, i.e.,

$$
P\left\{X_{j}=x_{j} \mid n \text { order lines in an order }\right\}=\left(\begin{array}{c}
n \\
x_{j}
\end{array}\right) P_{j}^{x_{j}}\left(1-P_{j}\right)^{n-x_{j}} \quad \forall j>C
$$

Canceling out the condition, we have

$$
\begin{aligned}
P\left\{X_{j}=x_{j}\right\} & =\sum_{n=1}^{N} P\left\{X_{j}=x_{j} \mid n \text { order lines in anorder }\right\} * O_{n} & \\
& =\sum_{n=1}^{N}\left(\begin{array}{l}
n \\
x_{j}
\end{array}\right) P_{j}^{x_{j}}\left(1-P_{j}\right)^{n-x_{j}} O_{n} & \forall j>C
\end{aligned}
$$

The expected number of lines to be picked at station $j$ given the bin enters station $j$ is:

$$
\begin{aligned}
E\left[X_{j} \mid x_{j}>0\right] & =\sum_{x_{j}=1}^{N} x_{j} * P\left\{X_{j}=x_{j} \mid x_{j}>0\right\} \\
& =\sum_{x_{j}=1}^{N} x_{j} * \frac{P\left\{X_{j}=x_{j}, x_{j}>0\right\}}{P\left\{X_{j}>0\right\}} \\
& =\frac{\sum_{x_{j}=1}^{N} x_{j} \sum_{n=1}^{N}\left(\begin{array}{l}
n \\
x_{j}
\end{array}\right) P_{j}^{x_{j}}\left(1-P_{j}\right)^{n-x_{j}} O_{n}}{1-P\left\{X_{j}=0\right\}} \quad \forall j>C
\end{aligned}
$$

To obtain the expected travel time, $E\left[w k_{j}\right]$, for an order bin, we need the information of the products' locations in a pick station. Under the pick-frequency class-based storage policy, the optimal locations of products and the picker's home base (pick position of order bins) in a pick station is illustrated in Error! Reference source not found. (see Jewkes et al. 2004), where 
class A refers to the class of those products with the highest demand frequency, class B the second highest class, and so on.



Conveyor

Picker's home base

Figure 2: Product locations in the storage rack at station $j$.

The expected travel time at station $j$ given that the order bin will enter station $j$ is:

$E\left[w k_{j}\right]=\frac{1}{w S} E\left[2 * \sum_{i}^{I} d_{i j} * X_{i j} \mid X_{j}>0\right] \quad \forall j>C$

Where ws is the travel speed of order pickers expressed in meter/second, $X_{i j}$ is the number of lines of the $i$ th class to be picked at station $j$, and $d_{i j}$ is the travel distance from the picker's home base to the location of the $i$ th class of products. $X_{i j}$ equals $X_{j} * \frac{p_{i j}}{P_{j}}$ in distribution. As mentioned before, we suppose that within each class, products are stored randomly and the demands are uniformly distributed over products. Hence $d_{i j}$ are uniformly distributed random variables with probability density function of:

$f_{d_{i j}}(x)= \begin{cases}\frac{2}{l_{i j}} & \text { for } \frac{1}{2} \sum_{k=0}^{i-1} l_{k j} \leq x \leq \frac{1}{2} \sum_{k=0}^{i} l_{k j} \quad \forall i, \forall j>C \\ 0 & \text { elsewhere }\end{cases}$

We define $l_{0 j}=0$ in the equation above. Because $d_{i j}$ are independent from $X_{j}$, and $\frac{p_{i j}}{P_{j}}$ are not random variables, we obtain

$E\left[w k_{j}\right]=\frac{2}{w s} E\left[X_{j} \mid X_{j}>0\right] * \sum_{i}^{I} \frac{p_{i j}}{P_{j}} E\left[d_{i j}\right] \quad \forall j>C$

Where, $E\left[d_{i j}\right]$ is the expected value of $d_{i j}$ given by

$E\left[d_{i j}\right]=\int_{-\infty}^{\infty} x f_{d_{i j}}(x) d x=\frac{1}{2} \sum_{k=0}^{i-1} l_{k j}+\frac{1}{4} l_{i j} \quad \forall i, \forall j>C$ 
Using equation (8), we can calculate the expected picking time at station $j$ given that the order bin will enter station $j$ :

$$
E\left[p k_{j}\right]=t p^{*} E\left[X_{j} \mid X_{j}>0\right] \quad \forall j>C
$$

From equation (1), (11) and (13), we can obtain the expected service time at station $j$ given that the order bin will enter station $j$.

To obtain the SCV of service time of an order bin at station $j$, we need to calculate the second moment of service time, which is given by

$$
\begin{aligned}
E\left[\tau_{j}^{2}\right] & =E\left[\left(w k_{j}+p k_{j}+s c\right)^{2}\right] \quad \forall j>C \\
& =E\left[w k_{j}^{2}\right]+E\left[p k_{j}^{2}\right]+2 E\left[w k_{j} p k_{j}\right]+2 s C^{*} E\left[w k_{j}\right]+2 s C^{*} E\left[p k_{j}\right]+s c^{2}
\end{aligned}
$$

The second moment of $w k_{j}$ is calculated as follows:

$$
\begin{aligned}
E\left[w k_{j}^{2}\right] & =\frac{4}{w s^{2}} E\left[X_{j}^{2} \mid X_{j}>0\right] * E\left[\left(\sum_{i=1}^{I} D_{i j}\right)^{2}\right] \\
& =\frac{4}{w s^{2}} E\left[X_{j}^{2} \mid X_{j}>0\right]^{*} E\left[2 * \sum_{i=1}^{I} \sum_{k=i+1}^{I}\left(D_{i j} D_{k j}\right)+\sum_{i=1}^{I} D_{i j}^{2}\right] \\
& =\frac{4}{w s^{2}} E\left[X_{j}^{2} \mid X_{j}>0\right] *\left\{2 * \sum_{i=1}^{I} \sum_{k=i+1}^{I} E\left[D_{i j}\right] E\left[D_{k j}\right]+E\left[\sum_{i=1}^{I} D_{i j}^{2}\right]\right\} \quad \forall j>C
\end{aligned}
$$

Where $D_{i j}=\frac{p_{i j}}{P_{j}} * d_{i j}$, and $E\left[D_{i j}\right]=\frac{p_{i j}}{P_{j}} E\left[d_{i j}\right]$

The last step of equation (15) follows from the independence of $D_{i j}$ and $D_{k j}$ if $i \neq k$. The conditional second moment of $X_{j}$ is given by:

$$
\begin{aligned}
E\left[X_{j}^{2} \mid X_{j}>0\right] & =\sum_{x_{j}=1}^{N} x_{j}^{2} * \frac{P\left\{X_{j}=x_{j}, x_{j}>0\right\}}{P\left\{X_{j}>0\right\}} \\
& =\frac{\sum_{x_{j}=1}^{N} x_{j}^{2} \sum_{n=1}^{N}\left(\begin{array}{l}
n \\
x_{j}
\end{array}\right) P_{j}^{x_{j}}\left(1-P_{j}\right)^{n-x_{j}} O_{n}}{P\left\{X_{j}>0\right\}} \quad \forall j>C
\end{aligned}
$$

The second moment of $D_{i j}$ is given below: 


$$
\begin{aligned}
E\left[D_{i j}^{2}\right] & =\left(\frac{p_{i j}}{P_{j}}\right)^{2} * E\left[d_{i j}^{2}\right] \\
& =\left(\frac{2}{l_{i j}}\right)\left(\frac{p_{i j}}{P_{j}}\right)^{2} * \int_{\frac{1}{2} \sum_{k=0}^{i-1} l_{k j}}^{\frac{1}{2} \sum_{k=0}^{i} l_{k j}} x^{2} d x \\
& =\frac{1}{3}\left(\frac{2}{l_{i j}}\right)\left(\frac{p_{i j}}{P_{j}}\right)^{2}\left[\left(\frac{1}{2} \sum_{k=0}^{i} l_{k j}\right)^{3}-\left(\frac{1}{2} \sum_{k=0}^{i-1} l_{k j}\right)^{3}\right] \quad \forall i, \forall j>C
\end{aligned}
$$

From equation (15) to (17), we obtain $E\left[w k_{j}^{2}\right]$. The second moment of $p k_{j}$ is obtained by

$$
E\left[p k_{k}^{2}\right]=t p^{2} * E\left[X_{j}^{2} \mid X_{j}>0\right]
$$

The component $E\left[w k_{j} p k_{j}\right]$ is calculated as

$$
\begin{aligned}
E\left[w k_{j} p k_{j}\right] & =\frac{1}{w s} E\left[2 *\left(\sum_{i=1}^{I} d_{i j} * \frac{p_{i j}}{P_{j}} * X_{j}\right) * t p * X_{j} \mid X_{j}>0\right] & \\
= & \frac{2 * t p}{w s} * E\left[X_{j}^{2} \mid X_{j}>0\right] *\left\{\sum_{i=1}^{I} \frac{p_{i j}}{P_{j}} * E\left[d_{i j}\right]\right\} & \forall j>C
\end{aligned}
$$

From equation (11)-(19), we can obtain the second moment of service time at a pick station given that the order bin will enter that station. With the value of the first and the second moment of service time, we can calculate the SCV of service time at station $j$

$$
c_{s j}^{2}=\frac{E\left[\tau_{j}^{2}\right]-E\left[\tau_{j}\right]^{2}}{E\left[\tau_{j}\right]^{2}} \quad \forall j>C
$$

As mentioned at the beginning of this section, the service rate of each server of a conveyor piece is constant; therefore the values of SCVs for conveyor pieces are zero, i.e.

$$
c_{s j}^{2}=0 \quad \forall j \leq C
$$

The mean service time of a server on a conveyor piece is the reciprocal of its service rate

$$
E\left[\tau_{j}\right]=\frac{k_{j}}{v l_{j}} \quad \forall j \leq C
$$

With the information of the mean and the SCV of service time at each node, we will calculate the order throughput time in the system in the next subsection. 


\subsection{Mean throughput time of an order}

We calculate the mean throughput time of an order bin in the pick-and-pass order picking system under consideration based on the $G / G / m$ queuing network approximation model of Whitt (1983, and 1993) (see appendix A). The mean order throughput time consists of transportation times on conveyor pieces, service times at pick stations, and the waiting times in front of conveyor pieces and pick stations. The approximation analysis uses two parameters to characterize the arrival process and the service time at each node, one to describe the rate, and the other to describe the variability. The two parameters for service time are $E\left[\tau_{j}\right]$, and $c_{s j}^{2}$, as we derived in section 3.1. For the arrival process, the parameters are $\lambda_{j}$, the arrival rate, which is the reciprocal of the mean inter-arrival time between two order bins to each node, and $c_{a j}^{2}$, the SCV of the inter-arrival time. Orders bins arrive at the system at conveyor piece 1 (see Figure 1 ) with rate $\lambda_{01}$, and the SCV of the inter-arrival time is $c_{01}^{2}$. To calculate the internal arrival rate and the SCV of inter-arrival time at each node, we need to know the transition probabilities between nodes. At the end of a conveyor piece, an order bin is either transferred to a subsequent conveyor piece for transportation or pushed into a pick station. The transition probabilities between these nodes are given by

$$
\begin{array}{ll}
q_{j j+C}=V_{j+C} & \forall j<C \\
q_{j j+1}=1-V_{j+C} & \forall j<C \\
q_{j j-S}=1 & \forall C<j \leq C+S
\end{array}
$$

Where the value of $V_{j+C}$ is obtained from equation (5). The transition probabilities between other nodes are zero. Because order bins leave the system from the last conveyor piece $C$, we have $q_{C j}=0$ for $\forall 1 \leq j \leq J$. The matrix of the transition probabilities is indicated by $Q$. As an example, consider a network with 3 pick stations and 4 conveyor pieces, i.e., $C=4$, and $S=3$. Assuming that at the end of each conveyor piece (except for piece 4, the last one), a bin has a probability of 0.6 to be pushed into the next pick station. Bins enter the system from node 1 and leave the system from node 4 . The Markov transition matrix is then given by 


$$
Q=\left(\begin{array}{lllllll}
0 & 0.4 & 0 & 0 & 0.6 & 0 & 0 \\
0 & 0 & 0.4 & 0 & 0 & 0.6 & 0 \\
0 & 0 & 0 & 0.4 & 0 & 0 & 0.6 \\
0 & 0 & 0 & 0 & 0 & 0 & 0 \\
0 & 1 & 0 & 0 & 0 & 0 & 0 \\
0 & 0 & 1 & 0 & 0 & 0 & 0 \\
0 & 0 & 0 & 1 & 0 & 0 & 0
\end{array}\right)
$$

With the probability transition matrix, we can obtain the internal traffic rates $\lambda_{j}$ and the SCV of the inter-arrival time between two bins to each node (see Appendix A).

The utilization of a conveyor piece and a pick station is given by

$\rho_{j}= \begin{cases}\lambda_{j} / v l_{j} & \forall j \leq C \\ \lambda_{j} E\left[\tau_{j}\right] / h_{j} & \forall j>C\end{cases}$

The expected sojourn time of a bin at node $j$ is given by

$$
E\left[T_{j}\right]=E\left[v t_{j}\right] *\left(E\left[W_{j}\right]+E\left[\tau_{j}\right]\right) \quad \forall 1 \leq j \leq J
$$

Where $E\left[W_{j}\right]$ is the expected waiting time in front of node $j$ as calculated by (A.9), and $E\left[v t_{j}\right]$ is the expected number of visits to node $j$ of an order bin. The probability mass function of $v t_{j}$ is given by

$v t_{j}=\left\{\begin{array}{l}0 \text { with probability } 1-V_{j} \\ 1 \text { with probability } V_{j}\end{array} \quad \forall 1 \leq j \leq J\right.$

Where $V_{j}$ is obtained from equation (5) for $j>C$ and $V_{j}=1$ for $j \leq C$. Hence

$$
E\left[v t_{j}\right]=0 *\left(1-V_{j}\right)+V_{j}=V_{j} \quad \forall 1 \leq j \leq J
$$

The total expected order throughput time is the summation of the expected sojourn time at each node.

\section{Model validation}

To validate the quality of the approximation method described in section 3, we compare the results with both simulation and a real order picking process.

We built a simulation model in Automod ${ }^{\circledR}$ 10.0. For each scenario in the example, we use at least 20,000 orders, preceded by 2000 orders of initialization for the system to become stable, to 
guarantee that the 95\%-confidence interval width of the Mean Order Throughput Time (MOTT) is below $1 \%$ of the mean value. The parameters used in the example are listed in Table 1.

Table 1: Parameters used in the example.

\begin{tabular}{|c|c|}
\hline Parameter & Value \\
\hline Order arrival process & $\begin{array}{l}\text { Poisson distributed (we evaluate different arrival } \\
\text { rates) }\end{array}$ \\
\hline Number of stations & 18 \\
\hline Number of order pickers & 18 \\
\hline Product classes and order frequency per class & Class 1: $f_{1}=0.8$, Class 2: $f_{2}=0.15$, Class 3: $f_{3}=0.05$ \\
\hline Total fraction of storage space for product classes & Class 1: 0.2, Class 2: 0.3, Class 3: 0.5 \\
\hline Size of order bins & $60 * 40 * 35 \mathrm{~cm}$ \\
\hline Conveyor speed & $\begin{array}{l}0.7 \text { bins per second }(0.1 \mathrm{~m} \text { minimum space } \\
\text { between two bins) }\end{array}$ \\
\hline Conveyor length & First piece 40 bins, 20 bins for others \\
\hline Length of each pick station & 28 meters ( 40 bins) \\
\hline Walk speed of order pickers & 1 meter/second \\
\hline Picking time per line & 18 seconds \\
\hline Setup time & 45 seconds \\
\hline Maximum number of lines in an order bin & 30 \\
\hline The number of order lines in an order & $\begin{array}{l}\text { Empirical distribution (based on the data from a } \\
\text { Dutch warehouse) with mean of } 15.6 \text { and standard } \\
\text { deviation of } 6.3\end{array}$ \\
\hline
\end{tabular}

Table 2 illustrates the storage assignments in stations and the probability that an order bin has to be handled at a station. We observe from Table 2 that stations have the same total storage space but use different storage space per product class (i.e., a non-uniform storage policy).

Table 2: Storage space and the bin visit probabilities to stations under the non-uniform storage policy.

\begin{tabular}{cccccccccc}
\hline $\boldsymbol{I}_{\mathbf{i j}}$ (meter) & St. 1 & St.2 & St. 3 & St. 4 & St. 5 & St.6 & St. 7 & St. 8 & St. 9 \\
clas1 & 4.9 & 5.6 & 6.3 & 4.9 & 5.6 & 6.3 & 4.9 & 5.6 & 4.9 \\
clas2 & 7.7 & 8.4 & 9.1 & 7.7 & 8.4 & 9.1 & 7.7 & 8.4 & 7.7 \\
clas3 & 15.4 & 14 & 12.6 & 15.4 & 14 & 12.6 & 15.4 & 14 & 15.4 \\
Bin visit prob. & 0.36 & 0.39 & 0.43 & 0.36 & 0.39 & 0.43 & 0.36 & 0.39 & 0.43 \\
& St. 10 & St.11 & St.12 & St. 13 & St. 14 & St.15 & St. 16 & St. 17 & St. 18 \\
clas1 & 6.3 & 4.9 & 5.6 & 6.3 & 4.9 & 5.6 & 6.3 & 4.9 & 5.6 \\
clas2 & 9.1 & 7.7 & 8.4 & 9.1 & 7.7 & 8.4 & 9.1 & 7.7 & 8.4 \\
clas3 & 12.6 & 15.4 & 14 & 12.6 & 15.4 & 14 & 12.6 & 15.4 & 14 \\
Bin visit prob. & 0.36 & 0.39 & 0.43 & 0.36 & 0.39 & 0.43 & 0.36 & 0.39 & 0.43 \\
\hline
\end{tabular}

We vary the order arrival rates to the system to compare the performance of the approximation method to simulation under different work loads. The results are listed in Table 3. Table 3 also illustrates the accuracy of G/G/m modeling over Jackson modeling used in De Koster (1994). 
Table 3: Validation results for the example and comparisons to Jackson modeling.

\begin{tabular}{|c|c|c|c|c|c|}
\hline \multirow{2}{*}{$\begin{array}{l}\text { Input rate } \\
\text { (bin/sec) }\end{array}$} & \multicolumn{4}{|c|}{ MOTT (sec)(G/G/m) } & \multirow{2}{*}{$\begin{array}{c}\text { MOTT(sec } \\
\text { (Jackson) }\end{array}$} \\
\hline & Numerical & Simulation & Rel. error & $\begin{array}{c}\text { Station } \\
\text { utilization (max) }\end{array}$ & \\
\hline 0.008 & 1615.5 & $1556.2 \pm 4.6$ & $3.81 \%$ & 0.409 & 1867.5 \\
\hline 0.011 & 1725.0 & $1647.3 \pm 5.2$ & $4.72 \%$ & 0.517 & 2119.9 \\
\hline 0.013 & 1889.8 & $1789.5 \pm 6.1$ & $5.60 \%$ & 0.630 & 2518.6 \\
\hline 0.016 & 2290.8 & $2171.5 \pm 8.3$ & $5.49 \%$ & 0.780 & 3559.0 \\
\hline 0.018 & 3116.0 & $3023.4 \pm 15.7$ & $3.06 \%$ & 0.893 & 5792.4 \\
\hline 0.019 & 4312.8 & $4247.4 \pm 24.4$ & $1.54 \%$ & 0.944 & 9078.5 \\
\hline
\end{tabular}

Table 3 shows that the relative errors between the approximation model and the simulation results are all below 6 percent under different work loads. It also shows that the larger the utilizations at stations, the more accurate $G / G / m$ modeling over Jackson modeling.

We also conducted other experiments with different parameters: the number of pick stations varied from 4 to 18 , with a step size of 2, and the utilization of pick stations varied from 0.2 to 0.9 with step size of 0.1 . In all experimental settings, the relative error between the approximation model and the simulation results were below $7 \%$.

To further validate our approximation method, we compare our results to the performance of a real order picking process in the bulky storage area at the parts distribution center of an international motor production company. The bulky storage area stores in total 240 products divided into 3 classes. One class contains 48 heavy products and the other two classes are categorized according to their order frequencies, each containing 96 products. The whole area is divided into four pick stations connected by conveyor pieces. Through analyzing the log files from the Warehouse Management System (WMS) for a picking day, which is chosen as a representative of its typical picking process, we obtained the data for the order arrival process to the system, the service times at pick stations, and the routing probabilities of order bins to enter each station. The results are listed in Table 4. We also measured the capacities of conveyor pieces and their moving speeds. We input these data into our approximation model. The result of MOTT is compared with the mean order throughput time obtained from the warehouse management system. 
Table 4: Data and comparison with results of the real order picking system.

\begin{tabular}{ll}
\hline Parameter & Value \\
\hline Number of stations & 4 \\
Number of order pickers per station & 1 \\
Number of order lines to pick per order & Empirical distribution (mean, 2.5, stdv, 1.9 ) \\
Order inter-arrival time to the system (sec) & Empirical distribution (mean, 28.9, stdv, 52.4) \\
Service time at station A (sec) & Empirical distribution (mean, 40.1, stdv, 41.6) \\
Service time at station B (sec) & Empirical distribution (mean, 51.0, stdv, 51.1) \\
Service time at station C (sec) & Empirical distribution (mean, 54.1, stdv, 48.0) \\
Service time at station D (sec) & Empirical distribution (mean, 38.8, stdv, 35.0) \\
Prob. To enter station A & 0.385 \\
Prob. To enter station B & 0.254 \\
Prob. To enter station C & 0.271 \\
Prob. To enter station D & 0.435 \\
MOTT from G/G/m approximation model (sec) & 302.1 \\
MOTT from WMS (sec) & 321.7 \\
Relative error & $6.1 \%$ \\
\hline
\end{tabular}

From Table 4, we find that the relative error is around 6 percent. We conclude that the quality of the approximation method is acceptable for practical purposes. In the next section, we use this approximation method as a tool to estimate the pick-and-pass order picking system performance under the various warehousing policies.

\section{Scenario analyses}

In this section, we use the approximation method to analyze the impact of different warehousing policies on the order picking system performance. These policies include the storage assignments in pick stations, the size of pick stations, the number of order pickers in stations, and order batching and splitting decisions in the order release process. The parameters used for these scenario analyses are illustrated in Table 1.

\subsection{The effects of storage policies on system performance}

Storage policies affect the order throughput time in the pick-and-pass system, as they impact the work load balance between stations. In this subsection, we will compare the impact of uniform (stations use identical storage spaces to store a certain class of products) and non-uniform (stations use different storage spaces to store a certain class of products) storage policies on mean order throughput time. We expect that the uniform storage policy leads to shorter order throughput time, as it leads to work load balance between stations. 
The storage space for each class of products in stations, and the probability for a bin to enter a pick station under the uniform storage policy are shown in Table 5.

Table 5: Storage space and the bin visit probabilities to stations under the uniform storage policy.

\begin{tabular}{cccccccccc}
\hline $\boldsymbol{I}_{\mathbf{i j}}$ (meter) & St. 1 & St.2 & St. 3 & St. 4 & St. 5 & St.6 & St. 7 & St. 8 & St. 9 \\
clas1 & 5.6 & 5.6 & 5.6 & 5.6 & 5.6 & 5.6 & 5.6 & 5.6 & 5.6 \\
clas2 & 8.4 & 8.4 & 8.4 & 8.4 & 8.4 & 8.4 & 8.4 & 8.4 & 8.4 \\
clas3 & 14 & 14 & 14 & 14 & 14 & 14 & 14 & 14 & 14 \\
Bin visit prob. & 0.39 & 0.39 & 0.39 & 0.39 & 0.39 & 0.39 & 0.39 & 0.39 & 0.39 \\
& St. 10 & St.11 & St.12 & St. 13 & St. 14 & St.15 & St. 16 & St. 17 & St. 18 \\
clas1 & 5.6 & 5.6 & 5.6 & 5.6 & 5.6 & 5.6 & 5.6 & 5.6 & 5.6 \\
clas2 & 8.4 & 8.4 & 8.4 & 8.4 & 8.4 & 8.4 & 8.4 & 8.4 & 8.4 \\
clas3 & 14 & 14 & 14 & 14 & 14 & 14 & 14 & 14 & 14 \\
Bin visit prob. & 0.39 & 0.39 & 0.39 & 0.39 & 0.39 & 0.39 & 0.39 & 0.39 & 0.39 \\
\hline
\end{tabular}

Table 6 illustrates the comparison with the non-uniform storage policy (refer to Table 2 and Table 3). As the stations are now balanced on average, we find from Table 6 that the mean order throughput times are shorter under the uniform storage policy than under the non-uniform storage policy. The improvement is substantial when the work load of the system increases.

Table 6: Comparison of system performance between uniform and non-uniform storage policies in pick stations.

\begin{tabular}{cccccc}
\hline & \multicolumn{3}{c}{ MOTT(sec) } & \multicolumn{2}{c}{ Utilization } \\
\hline Input rate (bin/sec) & Uniform & Non-uniform & Improvement & Uniform & Non-uniform \\
0.008 & 1613.0 & 1615.5 & $0.15 \%$ & 0.376 & 0.409 \\
0.011 & 1720.3 & 1725.0 & $0.27 \%$ & 0.475 & 0.517 \\
0.013 & 1876.4 & 1889.8 & $0.71 \%$ & 0.579 & 0.630 \\
0.016 & 2236.6 & 2290.8 & $2.37 \%$ & 0.716 & 0.780 \\
0.018 & 2849.1 & 3116.0 & $8.57 \%$ & 0.821 & 0.893 \\
0.019 & 3436.9 & 4312.8 & $20.31 \%$ & 0.868 & 0.944 \\
\hline
\end{tabular}

Because of the advantage of the uniform storage policy, we will focus our analysis on this storage policy in the following discussions.

\subsection{The effects of station sizes and the number of pickers on system performance}

The size of the pick stations and the number of order pickers in stations impact the mean order throughput time. With a fixed length of the whole order picking system (i.e., a fixed storage capacity of the system) and a fixed number of order pickers, the larger the size of the pick stations, the fewer number of stations we have in the system, and the more order pickers are 
available at each pick station. Pick stations of larger size will increase the service time due to longer picking travel time, and the fewer number of stations tends to increase the utilizations of pick stations due to higher order bin arrival rates. Therefore they lead to an increase of the mean order throughput time. But on the other hand, fewer number of stations leads to fewer station visits of an order bin (hence less queues and less setup time); more order pickers per station implies decreasing utilizations at pick stations, which reduces the mean order throughput time. In pick-and-pass order picking system design, a main question therefore is to find the right trade-off between these opposite effects by selecting the right number of stations. Table 7 shows the system performance for various combinations of station sizes and order pickers per station. It shows that under the current settings, the scenario of 6 stations with 3 order pickers per station has the best performance in all possible alternatives.

Table 7: System performances under various station sizes and the number of order pickers per station.

\begin{tabular}{|c|c|c|c|c|c|c|}
\hline \multicolumn{7}{|c|}{ \# of stations(\# of picker per station)(station size in meters) } \\
\hline \multirow[b]{2}{*}{$\begin{array}{c}\text { Input rate } \\
\text { (bin/sec) }\end{array}$} & \multicolumn{2}{|c|}{$18(1)(28)$} & \multicolumn{2}{|c|}{$9(2)(56)$} & \multicolumn{2}{|c|}{$6(3)(84)$} \\
\hline & $\begin{array}{c}\text { MOTT } \\
\text { (sec) }\end{array}$ & Utilization & $\begin{array}{c}\text { MOTT } \\
\text { (sec) }\end{array}$ & Utilization & $\begin{array}{c}\text { MOTT } \\
\text { (sec) }\end{array}$ & Utilization \\
\hline 0.008 & 1613.0 & 0.376 & 1370.7 & 0.348 & 1330.2 & 0.345 \\
\hline 0.011 & 1720.3 & 0.475 & 1407.9 & 0.439 & 1351.7 & 0.436 \\
\hline 0.013 & 1876.4 & 0.579 & 1463.7 & 0.535 & 1386.6 & 0.531 \\
\hline 0.016 & 2236.6 & 0.716 & 1586.9 & 0.663 & 1468.9 & 0.657 \\
\hline 0.018 & 2849.1 & 0.821 & 1765.7 & 0.759 & 1591.7 & 0.753 \\
\hline 0.019 & 3436.9 & 0.868 & 1904.3 & 0.803 & 1687.0 & 0.796 \\
\hline 0.020 & 4226.5 & 0.903 & 2052.3 & 0.835 & 1788.2 & 0.828 \\
\hline \multirow[t]{3}{*}{0.021} & 6110.2 & 0.940 & 2294.8 & 0.870 & 1951.6 & 0.863 \\
\hline & \multicolumn{6}{|c|}{ \# of stations(\# of picker per station)(station size in meters) } \\
\hline & \multicolumn{2}{|c|}{$3(6)(168)$} & \multicolumn{2}{|c|}{$2(9)(252)$} & \multicolumn{2}{|c|}{ 1(18)(514) } \\
\hline $\begin{array}{c}\text { Input rate } \\
\text { (bin/sec) }\end{array}$ & $\begin{array}{c}\text { MOTT } \\
\text { (sec) }\end{array}$ & Utilization & $\begin{array}{l}\text { MOTT } \\
\text { (sec) }\end{array}$ & Utilization & $\begin{array}{c}\text { MOTT } \\
\text { (sec) }\end{array}$ & Utilization \\
\hline 0.008 & 1426.6 & 0.398 & 1607.1 & 0.482 & 2304.4 & 0.771 \\
\hline 0.011 & 1441.2 & 0.503 & 1630.3 & 0.608 & 4867.1 & 0.974 \\
\hline 0.013 & 1474.0 & 0.612 & 1706.1 & 0.741 & inf & $>1$ \\
\hline 0.016 & 1587.6 & 0.758 & 2332.0 & 0.917 & inf & $>1$ \\
\hline 0.018 & 1870.8 & 0.868 & inf & $>1$ & inf & $>1$ \\
\hline 0.019 & 2263.9 & 0.918 & $\inf$ & $>1$ & inf & $>1$ \\
\hline 0.020 & 3113.5 & 0.955 & inf & $>1$ & inf & $>1$ \\
\hline 0.021 & 16765.0 & 0.994 & inf & $>1$ & inf & $>1$ \\
\hline
\end{tabular}




\subsection{The effects of batching orders on system performance}

As we have seen from the analysis above, the input rate of order bins to the system has great impact on system performance. A large arrival rate results in higher work load to the system, and will subsequently increase the mean order throughput time. One way to reduce the input rate to the system is to batch orders. We consider the following batching rules: We batch two successive order bins each containing at most $L$ lines into one bin, and then send it to the system. The order bins with larger than $L$ lines are sent directly to the system. The batching threshold, $L$ can take any value between 1 and $\left\lfloor\frac{N}{2}\right\rfloor$, where $\lfloor *\rfloor$ means rounding down to the nearest integer.

Otherwise, the number of lines in a batched bin may exceed the bin's capacity. We assume that $N$ (the maximum number of lines in an order) is also the capacity of an order bin. By batching small orders, we can decrease the input rate to the system, leading to decrease the mean order throughput time. On the other hand, the service time at each station and the probability of entering a pick station will increase because of more order lines to be picked. These factors lead to increase the mean order throughput time. When we batch two successive bins with fewer than $L$ lines, the first bin has to wait for several inter-arrival time periods to be processed. However, since the mean order inter-arrival time is normally very small compared to the total mean order throughput time, and only those bins containing less than $L$ lines are batched, this effect is small and can be neglected. The impact of order batching on system performance depends on the tradeoff between these factors. We can analyze this impact with a slight modification of the approximation method discussed above.

Assuming the original input process to the system is Poisson distributed with rate $\lambda_{01}$, an order bin has a probability $O_{n}$ to contain $n$ order lines. The flow of order bins with $n$ order lines is also a Poisson process with rate $\lambda_{01} * O_{n}$. After batching, the original process is split into two sub-processes. The first sub-process refers to the batched bins, and the second sub-process is the un-batched bins. According to the properties of Poisson process, the inter-arrival time of the first sub-process is Gamma distributed with parameters $\left(2, \lambda_{01} * \sum_{n=1}^{L} O_{n}\right)$. The input rate of this type of

order flow is $\tilde{\lambda}_{011}=\frac{1}{2} \lambda_{01} * \sum_{n=1}^{L} O_{n}$, and the SCV of the order inter-arrival time is $c_{011}^{2}=0.5$. The 
second sub-process is Poisson distributed with rate $\tilde{\lambda}_{012}=\lambda_{01} * \sum_{n=L+1}^{N} O_{n}$, where $N$ is the maximum number of lines in a bin. The SCV of the order inter-arrival time is $c_{012}^{2}=1$.

The basic idea to calculate the mean order throughput time with two input flows is derived from Whitt (1983). The procedure is first to calculate the mean and the SCV of service time at each pick station, the transition probabilities between nodes, and the internal traffic flows to each node separately for each input flow, and then we convert these two types of flows into one (See Appendix B). The method of Appendix A is again used to obtain the mean order throughput time. Following the example at the beginning of this section, we assume that $L$ equals 15 . Table 8 compares the system performance between batching and non-batching scenarios.

Table 8: Comparison of system performances between batching and non-batching scenarios.

\begin{tabular}{|c|c|c|c|c|c|c|c|}
\hline \multicolumn{8}{|c|}{$\mathrm{L}=15$} \\
\hline \multicolumn{2}{|c|}{ Order arrival rate (bins/sec) } & 0.0083 & 0.0105 & 0.0128 & 0.0159 & 0.0182 & 0.0185 \\
\hline \multicolumn{2}{|c|}{ Rate after batching (bins/sec) } & 0.0063 & 0.0079 & 0.0096 & 0.0119 & 0.0136 & 0.0138 \\
\hline \multirow[b]{2}{*}{ MOTPT (sec) } & Batching & 1864.2 & 1973.9 & 2123.4 & 2435.8 & 2891.8 & 2971.6 \\
\hline & Non-batching & 1613.0 & 1720.3 & 1876.4 & 2236.6 & 2849.1 & 2968.2 \\
\hline \multirow[b]{2}{*}{ Utilization } & Batching & 0.358 & 0.452 & 0.551 & 0.682 & 0.781 & 0.792 \\
\hline & Non-batching & 0.376 & 0.475 & 0.579 & 0.716 & 0.821 & 0.833 \\
\hline \multirow{2}{*}{$\begin{array}{c}\text { Mean waiting time } \\
\text { (sec) }\end{array}$} & Batching & 22.1 & 31.0 & 43.1 & 68.4 & 105.3 & 111.7 \\
\hline & Non-batching & 23.7 & 34.3 & 49.7 & 85.2 & 145.5 & 157.3 \\
\hline \multirow{2}{*}{$\begin{array}{l}\text { Mean service time } \\
\text { (sec) }\end{array}$} & Batching & 83.4 & 83.4 & 83.4 & 83.4 & 83.4 & 83.4 \\
\hline & Non-batching & 80.1 & 80.1 & 80.1 & 80.1 & 80.1 & 80.1 \\
\hline \multirow[b]{2}{*}{ Bin visiting prob. } & Batching & 0.69 & 0.69 & 0.69 & 0.69 & 0.69 & 0.69 \\
\hline & Non-batching & 0.56 & 0.56 & 0.56 & 0.56 & 0.56 & 0.56 \\
\hline \multicolumn{8}{|c|}{$\mathrm{L}=15$} \\
\hline \multicolumn{2}{|c|}{ Order arrival rate (bins/sec) } & 0.0186 & 0.0189 & 0.0192 & 0.0200 & 0.0204 & 0.0208 \\
\hline \multicolumn{2}{|c|}{ Rate after batching (bins/sec) } & 0.0139 & 0.0142 & 0.0144 & 0.0150 & 0.0153 & 0.0156 \\
\hline \multirow[b]{2}{*}{ MOTPT (sec) } & Batching & 3004.5 & 3114.5 & 3162.0 & 3679.9 & 3991.1 & 4424.2 \\
\hline & Non-batching & 3018.4 & 3191.7 & 3436.9 & 4226.5 & 4925.5 & 6110.2 \\
\hline \multirow[b]{2}{*}{ Utilization } & Batching & 0.797 & 0.810 & 0.826 & 0.859 & 0.876 & 0.895 \\
\hline & Non-batching & 0.837 & 0.852 & 0.868 & 0.903 & 0.921 & 0.940 \\
\hline \multirow{2}{*}{$\begin{array}{l}\text { Mean waiting time } \\
\text { (sec) }\end{array}$} & Batching & 114.4 & 123.3 & 135.2 & 169.0 & 194.2 & 229.2 \\
\hline & Non-batching & 162.2 & 179.3 & 203.5 & 281.3 & 350.1 & 466.9 \\
\hline \multirow{2}{*}{$\begin{array}{l}\text { Mean service time } \\
\text { (sec) }\end{array}$} & Batching & 83.4 & 83.4 & 83.4 & 83.4 & 83.4 & 83.4 \\
\hline & Non-batching & 80.1 & 80.1 & 80.1 & 80.1 & 80.1 & 80.1 \\
\hline \multirow[b]{2}{*}{ Bin visiting prob. } & Batching & 0.69 & 0.69 & 0.69 & 0.69 & 0.69 & 0.69 \\
\hline & Non-batching & 0.56 & 0.56 & 0.56 & 0.56 & 0.56 & 0.56 \\
\hline
\end{tabular}

Table 8 shows that the input rates decrease, and the service times at pick stations increase when orders are batched. Batching orders can slightly reduce the utilizations of pick stations. The 
impact of pick station utilizations on waiting times in front of stations is marginal when the utilizations are low, but becomes substantial when the utilizations get higher. We observe that when the system is not heavily loaded, order batching increases the mean order throughput time. This is mainly due to the longer service time at pick stations, and the increased probability of entering pick stations. However, when the system is heavily loaded, the mean order throughput time decreases when we batch orders. Under a heavy load, waiting time is the major component of the order throughput time; reducing pick stations utilizations by batching orders can significantly reduce waiting time in front of pick stations, and therefore reduces the mean order throughput time.

\subsection{The effects of splitting orders on system performance}

As an alternative to batching orders, splitting an order into two small orders will reduce the order bin service times in pick stations and the probabilities of entering pick stations. On the other hand, splitting orders increases the arrival flow rate because more order bins enter the system. To analyze the impact of order splitting on system performance, we split an order bin containing $R$ or more than $R$ lines into two bins, one containing $\lfloor R / 2\rfloor$ lines and the other containing $R$ $\lfloor R / 2\rfloor$ lines. Again, assuming the original arrival process is Poisson distributed, the input process is divided into two Poisson processes: the input flow of non-split bins with rate $\tilde{\lambda}_{011}=\lambda_{01} * \sum_{n=1}^{R-1} O_{n}$, and the input flow of bins to be split with rate $\tilde{\lambda}_{012}=\lambda_{01} * \sum_{n=R}^{N} O_{n}$. Before arriving at the first conveyor piece, we suppose the input flow of bins to be split will first pass through an artificial node with very small constant service time. A new order bin is created following the completion of service at the artificial node. According to the approximation method given at section 2.2 and 4.6 of Whitt 1983, the departure process, i.e., the arrival process to the first conveyor piece of this flow of split bins has rate of $2 * \tilde{\lambda}_{012}$, and approximated SCV of inter-arrival time of 2.

The total arrival process to the first conveyor piece is therefore the combination of a Poisson process, with rate $\tilde{\lambda}_{011}=\lambda_{01} * \sum_{n=1}^{R-1} O_{n}$, and a process with rate of $2 * \tilde{\lambda}_{012}$ and SCV of inter-arrival time of 2. Similar to the approaches used to analyze batching orders, we can obtain the system 
performance for the order splitting scenario. The results with comparison to the non-splitting scenario, as illustrated in Table 9, show that splitting orders increases the input rate to the system and reduces the service times at pick stations and the probabilities of entering pick stations. Splitting orders increases the utilizations of pick stations. The mean order throughput time shortens when the station utilizations are low. This is mainly due to the reduction in service times and the probabilities of entering pick stations. When station utilization becomes high ( $\rho>0.75$ approximately for $R$ equals 15 ), order splitting increases the mean order throughput time because the waiting time in front of a station becomes longer due to higher utilization.

Table 9: Comparison of system performances between splitting and non-splitting scenario.

\begin{tabular}{|c|c|c|c|c|c|c|c|}
\hline \multicolumn{8}{|c|}{$\mathrm{R}=15$} \\
\hline \multicolumn{2}{|c|}{ Order arrival rate (bins/sec) } & 0.0083 & 0.0105 & 0.0128 & 0.0159 & 0.0164 & 0.0166 \\
\hline \multicolumn{2}{|c|}{ Rate after splitting (bins/sec) } & 0.0130 & 0.0164 & 0.0200 & 0.0248 & 0.0256 & 0.0259 \\
\hline \multirow[b]{2}{*}{ MOTPT (sec) } & Splitting & 1344.6 & 1451.1 & 1624.1 & 2128.2 & 2295.8 & 2369.6 \\
\hline & Non-splitting & 1613.0 & 1720.3 & 1876.4 & 2236.6 & 2333.2 & 2372.8 \\
\hline \multirow[b]{2}{*}{ Utilization } & Splitting & 0.416 & 0.526 & 0.640 & 0.793 & 0.819 & 0.828 \\
\hline & Non-splitting & 0.376 & 0.475 & 0.579 & 0.716 & 0.740 & 0.749 \\
\hline \multirow{2}{*}{$\begin{array}{c}\text { Mean waiting time } \\
\text { (sec) }\end{array}$} & Splitting & 26.9 & 40.5 & 63.0 & 128.2 & 149.8 & 159.3 \\
\hline & Non-splitting & 23.7 & 34.3 & 49.7 & 85.2 & 94.7 & 98.6 \\
\hline \multirow{2}{*}{$\begin{array}{l}\text { Mean service time } \\
\text { (sec) }\end{array}$} & Splitting & 74.5 & 74.5 & 74.5 & 74.5 & 74.5 & 74.5 \\
\hline & Non-splitting & 80.1 & 80.1 & 80.1 & 80.1 & 80.1 & 80.1 \\
\hline \multirow[b]{2}{*}{ Bin visiting prob. } & Splitting & 0.43 & 0.43 & 0.43 & 0.43 & 0.43 & 0.43 \\
\hline & Non-splitting & 0.56 & 0.56 & 0.56 & 0.56 & 0.56 & 0.56 \\
\hline \multicolumn{8}{|c|}{$\mathrm{R}=15$} \\
\hline \multicolumn{2}{|c|}{ Order arrival rate (bins/sec) } & 0.0167 & 0.0169 & 0.0172 & 0.0175 & 0.0182 & 0.0192 \\
\hline \multicolumn{2}{|c|}{ Rate after splitting (bins/sec) } & 0.0260 & 0.0264 & 0.0269 & 0.0274 & 0.0284 & 0.0300 \\
\hline \multirow[b]{2}{*}{ MOTPT (sec) } & Splitting & 2404.3 & 2536.4 & 2700.9 & 2911.8 & 3581.9 & 7023.3 \\
\hline & Non-splitting & 2390.9 & 2456.6 & 2532.3 & 2620.4 & 2849.1 & 3436.9 \\
\hline \multirow[b]{2}{*}{ Utilization } & Splitting & 0.833 & 0.847 & 0.861 & 0.876 & 0.908 & 0.961 \\
\hline & Non-splitting & 0.752 & 0.765 & 0.778 & 0.792 & 0.821 & 0.868 \\
\hline \multirow{2}{*}{$\begin{array}{c}\text { Mean waiting time } \\
\text { (sec) }\end{array}$} & Splitting & 163.8 & 180.9 & 202.2 & 229.4 & 316.0 & 760.6 \\
\hline & Non-splitting & 100.4 & 106.8 & 114.3 & 123.0 & 145.5 & 203.5 \\
\hline \multirow{2}{*}{$\begin{array}{l}\text { Mean service time } \\
\text { (sec) }\end{array}$} & Splitting & 74.5 & 74.5 & 74.5 & 74.5 & 74.5 & 74.5 \\
\hline & Non-splitting & 80.1 & 80.1 & 80.1 & 80.1 & 80.1 & 80.1 \\
\hline \multirow[b]{2}{*}{ Bin visiting prob. } & Splitting & 0.43 & 0.43 & 0.43 & 0.43 & 0.43 & 0.43 \\
\hline & Non-splitting & 0.56 & 0.56 & 0.56 & 0.56 & 0.56 & 0.56 \\
\hline
\end{tabular}

We note that the approximation model underestimates the mean order throughput time when we consider each split as a separate order. However, in reality, orders are only split when the number of order lines is large, and the impact on mean throughput time will be slight. The 
approximation model will give a reasonable estimation for the mean order throughput time from a practical point of view.

\section{Conclusions and extensions}

In this paper, we propose an approximation method based on $G / G / m$ queuing network modeling to analyze performance of a pick-and-pass order picking system. The method can be used as a fast tool to estimate design alternatives on the mean order throughput time of the order picking system. These alternatives include the storage policies, the size of pick stations, the number of order pickers in stations, and the arrival process of customer orders. In general, the preference of one alternative over others is subject to a detailed specification of the order picking system. The quality of the approximation method is acceptable for practical purposes. Therefore it enables planners to evaluate various system alternatives, which is essential at the design phase of the order picking system. Additionally, the approximation method can also be used to evaluate various operational policies like order batching and order splitting on system performance.

The model lends itself to several modifications and extensions left for future research. Although we assumed in this paper pickers pick only one order line in their picking tour, it is possible to relax this assumption and derive the first and second moment of service time for picking multiple lines in a pick tour. We may also take the number of units to pick in an order line into consideration and differentiate the picking time for different articles. In such cases, the number of units to pick in an order line and the picking time per article are both stochastic variables. The G/G/m queuing network approximation model still can be used to analyze these situations, but characterizing the distribution is less straightforward. The $G / G / m$ queuing network approximation model still can be used to analyze this situation. The layout of pick stations can be altered (we here assumed a line layout) to, for example, a parallel-aisle layout. We also estimated the standard deviation of order throughput time using the method described in Whitt (1983). However, the method did not provide good estimation results. It would also be interesting to find a more accurate approach to estimate the standard deviation of order throughput time, which together with mean order throughput time provides a better description of the order picking system performance. Another interesting extension of the paper is to consider the situation that an order picker is responsible for the pickings at multiple pick stations. Furthermore, in reality, the buffer capacity in front of each pick station is finite, which influences performance in high- 
utilization situations. It might be possible to derive estimates for the mean throughput time using approximation methods for finite buffer queuing networks.

\section{References}

Caron, F., Marchet, G. and Perego A. (1998) Routing policies and COI-based storage policies in picker-to-part systems. International Journal of Production Research, 36(3), 713-732.

Chew, E. and Tang, L. C. (1999) Travel time analysis for general item location assignment in a rectangular warehouse. European Journal of Operational Research, 112(3), 582-597.

De Koster, R. (1994) Performance approximation of pick-to-belt order picking systems. European Journal of Operational Research, 72, 558-573.

De Koster, R. (1996) On the design of a high capacity pick-and-pass order picking system, in Progress in Material Handling Research, Material Handling Institute, Charlotte, NC. pp.253-269. De Koster, R, Le Duc, T. and Roodbergen, K. J. (2007) Design and control of warehouse order picking: a literature review. European Journal of Operational Research, 182(2), 481-501.

De Koster, M.B.M., Van De Poort, E.S. and Wolters, M. (1999) Efficient order batching methods in warehouses. International Journal of Production Research, 37(7), 1479-1504.

Elsayed, E.A. and Stern, R.G. (1983) Computerized algorithms for order processing in automated warehousing systems. International Journal of Production Research, 21(4), 579-586.

Elsayed, E.A. and Unal, O.L. (1989) Order batching algorithms and travel-time estimation for automated storage/retrieval systems. International Journal of Production Research, 29, 10971114.

Gademann, N., Van den Berg, J.P. and Van der Hoff, H.H. (2001) An order batching algorithm for wave picking in a parallel-aisle warehouse. IIE transactions, 33, 385-398.

Gademann, N. and Van de Velder, S. (2005) Order batching to minimize total travel time in a parallel-aisle warehouse. IIE transactions, 37(1), 63-75.

Gibson, D.R. and Sharp, G.P. (1992) Order batching procedures. European Journal of Operational Research, 58(1), 57-67.

Goetschalckx, M. and Ashayeri, J. (1989) Classification and design of order picking systems. Logistics World, June, 99-106.

Graves, S.C., Hausman, W.H. and Schwarz, L.B. (1977) Storage-retrieval interleaving in automatic warehousing systems. Management Science, 23(9), 935-945. 
Gu, J., Goetschalckx, M. and McGinnis, L.F. (2007) Research on warehouse operation: A comprehensive review. European Journal of Operational Research, 177(1), 1-21.

Hwang, H., Baek, W. and Lee, M.K. (1988) Clustering algorithms for order picking in an automated storage and retrieval system. International Journal of Production Research, 26(2), 189-201.

Jane, C.C. (2000) Storage location assignment in a distribution center. International Journal of Physical and Logistics Management, 30(1), 55-71.

Jane, C.C. and Laih, Y.W. (2005) A clustering algorithm for item assignment in a synchronized zone order picking system. European Journal of Operational Research, 166, 489-496.

Jarvis, J.M. (1991) Optimal product layout in an order picking warehouse. IIE transactions, 23(1), 93-102.

Jewkes, E., Lee, C. and Vickson, R. (2004) Product location, allocation and server home base location for an order picking line with multiple servers. Computer \& Operations Research, 31, 623-636.

Le-Duc, T. (2005) Design and control of efficient order picking processes, Ph.D. Thesis, Erasmus Research Institute of Management (ERIM), RSM Erasmus University, the Netherlands. Le-Duc, T. and De Koster, M.B.M. (2007) Travel time estimation and order batching in a 2block warehouse. European Journal of Operational Research, 176(1), 374-386.

Le-Duc, T. and De Koster, M.B.M. (2005) On determine the optimal number of zones in a pickand-pack order picking system. Report, Erasmus Research Institute of Management (ERIM), RSM Erasmus University, the Netherlands.

Pan, C.H. and Liu, S.Y. (1995) A comparative study of order batching algorithms. Omega International Journal of Management Science, 23(6), 691-700.

Petersen, C.G., Aase, G. and Heiser, D.R. (2004) Improving order-picking performance through the implementation of class-based storage. International Journal of Physical Distribution and Logistics Management, 34(7), 534-544.

Ratliff, H.D., and Rosenthal, A.S. (1983) Order picking in a rectangular warehouse: a solvable case of traveling salesman problem. Operations Research, 31(3), 507-521.

Roodbergen, K.J. (2001) Layout and routing methods for warehouses, Ph.D. Thesis, Erasmus Research Institute of Management (ERIM), RSM Erasmus University, the Netherlands. Roodbergen, K.J. and De Koster, R. (2001) Routing order pickers in a warehouse with a middle 
aisle. European Journal of Operational Research, 133, 32-43.

Tompkins, J.A., White, J.A., Bozer, Y.A., Frazelle, E.H. and Tanchoco, J.M.A. (2003) Facilities Planning, John Wiley \& Sons, Hoboken, NJ.

Van den Berg, J.P. (1999) A literature survey on planning and control of warehousing systems.

IIE Transactions, 31(8), 751-762.

Whitt, W. (1983) The queuing network analyzer. The Bell System Technical Journal, 62(9), 2779-2815.

Whitt, W. (1993) Approximations for the $\mathrm{GI} / \mathrm{G} / \mathrm{m}$ queue. Production and Operations Management, 2(2), 114-159. 


\section{Appendix A}

According to Whitt (1983), to estimate the mean order throughput time in this $G / G / m$ queuing network system, we need to calculate the internal flow parameters. The internal flow rate to each node, $\lambda_{j}$, is obtained by solving the following linear equations

$\lambda_{j}=\lambda_{0 j}+\sum_{i=1}^{J} \lambda_{i} q_{i j} \quad 1 \leq j \leq J$

Where $\lambda_{0 j}$ is the external arrival rate to node $j, J$ is the total number of nodes (conveyor pieces and pick stations) in the system, and $q_{i j}$ is the transition probability from node $i$ to node $j$.

The arrival rate to node $j$ from node $i$ is given by

$\lambda_{i j}=\lambda_{i} q_{i j} \quad \forall 1 \leq i \leq J, \forall 1 \leq j \leq J$

The proportion of arrivals to $j$ that come from $i$, is calculated by

$p r_{i j}=\lambda_{i j} / \lambda_{j} \quad \forall 0 \leq i \leq J, \forall 1 \leq j \leq J$

The variability parameters of the internal flow, i.e. the SCVs of the inter-arrival time of the arrival processes to nodes, are calculated by solving the following linear equations

$c_{a j}^{2}=a_{j}+\sum_{i=1}^{J} c_{a i}^{2} b_{i j} \quad 1 \leq j \leq J$

where

$\left.a_{j}=1+\omega_{j}\left\{\left(p r_{0 j} c_{0 j}^{2}-1\right)+\sum_{i=1}^{J} p r_{i j}\left[\left(1-q_{i j}\right)+q_{i j} \rho_{i}^{2} x_{i}\right]\right\}\right\}$

$b_{i j}=\omega_{j} p r_{i j} q_{i j}\left(1-\rho_{i}^{2}\right)$

$c_{0 j}^{2}$ is the SCV of the external inter-arrival time to node $j$, and $c_{0 j}^{2}=0$ for $\forall j>1$, since the order bins enter the system from the first conveyor piece.

$\rho_{i}$ is the utilization of node $i$ obtained from equation (26), and

$x_{i}=1+m_{i}^{-0.5}\left(\max \left\{c_{s i}^{2}, 0.2\right\}-1\right)$

with $m_{i}$ the number of servers at node $i$, and $c_{s i}^{2}$ the SCV of service time at node $i$ obtained from equation (20) and (21). 
$\omega_{j}=\left[1+4\left(1-\rho_{j}\right)^{2}\left(v_{j}-1\right)\right]^{-1}$

with $v_{j}=\left[\sum_{i=0}^{J} p r_{i j}^{2}\right]^{-1}$.

With the internal flow parameters, $\lambda_{j}$ and $c_{a j}^{2}$, and the service time parameters, $E\left[\tau_{j}\right]$, and $c_{s j}^{2}$, Whitt (1983) decomposes the network into separate service facilities that are analyzed in isolation. Each service facility is a $G / G / m$ queue. Whitt (1993) provides the following approximation for the expected waiting time in queues. Since we are focusing on a single node, we omit the subscript indexing the node in deriving the expected waiting time in front of a node. For a multi-server node with $m$ servers, the expected waiting time is given by

$$
E[W]_{G / G / m}=\phi\left(\rho, c_{a}^{2}, c_{s}^{2}, m\right)\left(\frac{c_{a}^{2}+c_{s}^{2}}{2}\right) E[W]_{M / M / m}
$$

where $c_{a}^{2}$ and $c_{s}^{2}$ are obtained from (A.4), and equation (20) and (21) respectively, $\rho$ is given by equation (26), $E[W]_{M / M / m}$ is the waiting time in queue of a multi-server node with Poisson arrivals and exponential service distribution. The exact expression for $E[W]_{M / M / m}$ is given by

$$
E[W]_{M / M / m}=\frac{P(N \geq m)}{\mu m(1-\rho)}
$$

where $\mu$ is the reciprocal of mean service time at each node.

$P(N \geq m)$ is the probability that all servers are busy and is given by

$P(N \geq m)=\left(\frac{(m \rho)^{m}}{m !(1-\rho)}\right) \zeta$

with $\zeta=\left(\frac{(m \rho)^{m}}{m !(1-\rho)}+\sum_{k=0}^{m-1} \frac{(m \rho)^{k}}{k !}\right)^{-1}$

The expression for $\phi$ in (A.9) is given by

$$
\phi\left(\rho, c_{a}^{2}, c_{s}^{2}, m\right)= \begin{cases}\left(\frac{4\left(c_{a}^{2}-c_{s}^{2}\right)}{4 c_{a}^{2}-3 c_{s}^{2}}\right) \phi_{1}(m, \rho)+\left(\frac{c_{s}^{2}}{4 c_{a}^{2}-3 c_{s}^{2}}\right) \psi\left(c^{2}, m, \rho\right) & c_{a}^{2} \geq c_{s}^{2} \\ \left(\frac{c_{s}^{2}-c_{a}^{2}}{2\left(c_{a}^{2}+c_{s}^{2}\right.}\right) \phi_{3}(m, \rho)+\left(\frac{c_{s}^{2}+3 c_{a}^{2}}{2\left(c_{a}^{2}+c_{s}^{2}\right.}\right) \psi\left(c^{2}, m, \rho\right) & c_{a}^{2} \leq c_{s}^{2}\end{cases}
$$

with

$\phi_{1}(m, \rho)=1+\gamma(m, \rho)$ 


$$
\begin{aligned}
& \phi_{3}(m, \rho)=(1-4 \gamma(m, \rho)) e^{\frac{-2(1-\rho)}{3 \rho}} \\
& \gamma(m, \rho)=\min \left\{0.24, \frac{(1-\rho)(m-1)\left[(4+5 m)^{0.5}-2\right]}{16 m \rho}\right\}
\end{aligned}
$$

and

$\psi\left(c^{2}, m, \rho\right)= \begin{cases}1 & c^{2}>1 \\ \phi_{4}(m, \rho)^{2\left(1-c^{2}\right)} & 0 \leq c^{2} \leq 1\end{cases}$

with $c^{2}=\frac{c_{a}^{2}+c_{s}^{2}}{2}$ and $\phi_{4}(m, \rho)=\min \left\{1, \frac{\phi_{1}(m, \rho)+\phi_{3}(m, \rho)}{2}\right\}$. 


\section{Appendix B}

Based on the work of Whitt (1983), we convert the two input flows into one. The external arrival rate to the system is given by

$\lambda_{01}=\tilde{\lambda}_{011}+\tilde{\lambda}_{012}$

where $\lambda_{01}$ is the combined external arrival rate to the system, $\tilde{\lambda}_{011}$ and $\tilde{\lambda}_{012}$ are the two separate external arrival rates to the system. The internal traffic rate to node $j$ is given by

$\lambda_{j}=\tilde{\lambda}_{j 1}+\tilde{\lambda}_{j 2} \quad \forall 1 \leq j \leq J$

where $\tilde{\lambda}_{j 1}$ and $\tilde{\lambda}_{j 2}$ are the internal traffic rates to node $j$ from each input flow solved by the linear equations of (A.1).

The mean service time at pick station $j$ is the weighted combination of the service times for two separate input flows

$$
E\left[\tau_{j}\right]=\frac{\tilde{\lambda}_{j 1} E\left[\tau_{j 1}\right]+\tilde{\lambda}_{j 2} E\left[\tau_{j 2}\right]}{\tilde{\lambda}_{j 1}+\tilde{\lambda}_{j 2}} \quad \forall j>C
$$

where $E\left[\tau_{j 1}\right]$ and $E\left[\tau_{j 2}\right]$ are the mean service time for each separate input flow derived from equation (1).

The second moment of service time at pick station $j$ is derived by

$$
E\left[\tau_{j}^{2}\right]=\frac{\tilde{\lambda}_{j 1} E\left[\tau_{j 1}^{2}\right]+\tilde{\lambda}_{j 2} E\left[\tau_{j 2}^{2}\right]}{\tilde{\lambda}_{j 1}+\tilde{\lambda}_{j 2}} \forall j>C
$$

where $E\left[\tau_{j 1}^{2}\right]$ and $E\left[\tau_{j 2}^{2}\right]$ are the second moments of service time at pick station $j$ for each input flow given by equation (14).

The SCV of service time at pick station $j, c_{s j}^{2}$, can then be calculated from equation (20), (B.3), and (B.4). Because the service time is constant at conveyor pieces, the SCV and the mean of service time are obtained from equation (21) and (22).

The SCV of inter-arrival time to each node, $c_{a j}^{2}$, is again obtained from (A.4). The required parameters are calculated as follows: 
The transition probabilities from node $i$ to node $j$ are calculated as

$q_{i j}= \begin{cases}\lambda_{i j} / \lambda_{01} & \forall 1 \leq i \leq C, j=i+1, \text { and } j=i+C \\ 1 & \forall C+1 \leq i \leq J, j=i-C\end{cases}$

$\lambda_{i j}$, the arrival rate from node $i$ to node $j$ is given by

$\lambda_{i j}=\tilde{\lambda}_{i j 1}+\tilde{\lambda}_{i j 2} \quad \forall 1 \leq i \leq J, \forall 1 \leq j \leq J$

where $\tilde{\lambda}_{i j 1}$ and $\tilde{\lambda}_{i j 2}$ are the arrival rates from node $i$ to node $j$ for each separate input flow derived from (A.2).

The utilizations $\rho_{j}$ at each node $j$, are calculated from equation (26).

$p r_{i j}$, the proportion of arrivals to $j$ that come from $i(i \geq 0)$, is obtained from (A.3).

The SCV for the inter-arrival time of orders to the system is given by

$c_{01}^{2}=\left(1-\tilde{\omega}_{1}\right)+\tilde{\omega}_{1}\left[c_{011}^{2}\left(\frac{\tilde{\lambda}_{011}}{\tilde{\lambda}_{011}+\tilde{\lambda}_{012}}\right)+c_{012}^{2}\left(\frac{\tilde{\lambda}_{012}}{\tilde{\lambda}_{011}+\tilde{\lambda}_{012}}\right)\right]$

where $\tilde{\omega}_{1}=\left[1+4\left(1-\rho_{1}\right)^{2}\left(\tilde{v}_{1}-1\right)\right]^{-1}$ with $\rho_{1}=\lambda_{01} E\left[\tau_{1}\right] / m_{1}$ and $\tilde{v}_{1}=\left[\left(\frac{\tilde{\lambda}_{011}}{\tilde{\lambda}_{011}+\tilde{\lambda}_{012}}\right)^{2}+\left(\frac{\tilde{\lambda}_{012}}{\tilde{\lambda}_{011}+\tilde{\lambda}_{012}}\right)^{2}\right]$

$c_{011}^{2}$ and $c_{012}^{2}$ are the SCV for the inter-arrival time of orders to the system of each separate input flow.

At this point, we have converted the two input flows into one. We can apply the procedures in Appendix A to calculate the expected waiting time in front of each node and subsequently use equation (27) to obtain the expected sojourn time of a bin at a node. 


\section{Publications in the Report Series Research ${ }^{*}$ in Management}

\section{ERIM Research Program: "Business Processes, Logistics and Information Systems"}

2007

India: a Case of Fragile Wireless Service and Technology Adoption?

L-F Pau and J. Motiwalla

ERS-2007-011-LIS

http://hdl.handle.net/1765/9043

Some Comments on the Question Whether Co-occurrence Data Should Be Normalized

Ludo Waltman and Nees Jan van Eck

ERS-2007-017-LIS

http://hdl.handle.net/1765/9401

Extended Producer Responsibility in the Aviation Sector

Marisa P. de Brito, Erwin A. van der Laan and Brijan D. Irion

ERS-2007-025-LIS

http://hdl.handle.net/1765/10068

Logistics Information and Knowledge Management Issues in Humanitarian Aid Organizations

Erwin A. van der Laan, Marisa P. de Brito and S. Vermaesen

ERS-2007-026-LIS

http://hdl.handle.net/1765/10071

Bibliometric Mapping of the Computational Intelligence Field

Nees Jan van Eck and Ludo Waltman

ERS-2007-027-LIS

http://hdl.handle.net/1765/10073

Approximating the Randomized Hitting Time Distribution of a Non-stationary Gamma Process

J.B.G. Frenk and R.P. Nicolai

ERS-2007-031-LIS

http://hdl.handle.net/1765/10149

Application of a General Risk Management Model to Portfolio Optimization Problems with Elliptical Distributed Returns for Risk Neutral and Risk Averse Decision Makers

Bahar Kaynar, S. Ilker Birbil and J.B.G. Frenk

ERS-2007-032-LIS

http://hdl.handle.net/1765/10151

Optimal Zone Boundaries for Two-class-based Compact 3D AS/RS

Yugang Yu and M.B.M. de Koster

ERS-2007-034-LIS

http://hdl.handle.net/1765/10180

Portfolios of Exchange Relationships: An Empirical Investigation of an Online Marketplace for IT Services

Uladzimir Radkevitch, Eric van Heck and Otto Koppius

ERS-2007-035-LIS

http://hdl.handle.net/1765/10072

From Closed-Loop to Sustainable Supply Chains: The WEEE case

J. Quariguasi Frota Neto, G. Walther, J.Bloemhof, J.A.E.E van Nunen and T.Spengler

ERS-2007-036-LIS

http://hdl.handle.net/1765/10176 
A Methodology for Assessing Eco-Efficiency in Logistics Networks

J. Quariguasi Frota Neto, G. Walther, J.Bloemhof, J.A.E.E van Nunen and T.Spengler

ERS-2007-037-LIS

http://hdl.handle.net/1765/10177

Strategic and Operational Management of Supplier Involvement in New Product Development: a Contingency Perspective Ferrie E.A. van Echtelt, Finn Wynstra and Arjan J. van Weele

ERS-2007-040-LIS

http://hdl.handle.net/1765/10456

How Will Online Affiliate Marketing Networks Impact Search Engine Rankings?

David Janssen and Eric van Heck

ERS-2007-042-LIS

http://hdl.handle.net/1765/10458

Modelling and Optimizing Imperfect Maintenance of Coatings on Steel Structures

R.P. Nicolai, J.B.G. Frenk and R. Dekker

ERS-2007-043-LIS

http://hdl.handle.net/1765/10455

Human Knowledge Resources and Interorganizational Systems

Mohammed Ibrahim, Pieter Ribbers and Bert Bettonvil

ERS-2007-046-LIS

http://hdl.handle.net/1765/10457

Revenue Management and Demand Fulfilment: Matching Applications, Models, and Software

Rainer Quante, Herbert Meyr and Moritz Fleischmann

ERS-2007-050-LIS

http://hdl.handle.net/1765/10464

Mass Customization in Wireless Communication Services: Individual Service Bundles and Tariffs

Hong Chen and Louis-Francois Pau

ERS-2007-051-LIS

http://hdl.handle.net/1765/10515

Individual Tariffs for Mobile Services: Analysis of Operator Business and Risk Consequences

Hong Chen and Louis-Francois Pau

ERS-2007-052-LIS

http://hdl.handle.net/1765/10516

Individual Tariffs for Mobile Services: Theoretical Framework and a Computational Case in Mobile Music

Hong Chen and Louis-Francois Pau

ERS-2007-053-LIS

http://hdl.handle.net/1765/10517

Individual Tariffs for Mobile Communication Services

Hong Chen and Louis-Francois Pau

ERS-2007-054-LIS

http://hdl.handle.net/1765/10518

Is Management Interdisciplinary? The Evolution of Management as an Interdisciplinary Field of Research and Education in the Netherlands

Peter van Baalen and Luchien Karsten

ERS-2007-047-LIS

http://hdl.handle.net/1765/10537 
Detecting and Forecasting Economic Regimes in Multi-Agent Automated Exchanges Wolfgang Ketter, John Collins, Maria Gini, Alok Gupta and Paul Schrater

ERS-2007-065-LIS

http://hdl.handle.net/1765/10594

Emergency Messaging to General Public via Public Wireless Networks

P.Simonsen and L-F Pau

ERS-2007-078-LIS

http://hdl.handle.net/1765/10718

Flexible Decision Control in an Autonomous Trading Agent

John Collins, Wolfgang Ketter and Maria Gini

ERS-2007-079-LIS

http://hdl.handle.net/1765/10719

Discovering the Dynamics of Smart Business Networks

L-F Pau

ERS-2007-081-LIS

http://hdl.handle.net/1765/10732

Performance Approximation and Design of Pick-and-Pass Order Picking Systems

Mengfei Yu and René de Koster

ERS-2007-082-LIS

http://hdl.handle.net/1765/10733

* A complete overview of the ERIM Report Series Research in Management: https://ep.eur.nl/handle/1765/1

ERIM Research Programs:

LIS Business Processes, Logistics and Information Systems

ORG Organizing for Performance

MKT Marketing

F\&A Finance and Accounting

STR Strategy and Entrepreneurship 